\title{
Mechanochemical Synthesis of Lead Magnesium Niobate Ceramics in Iron Media
}

\author{
Z. BRANKOVIĆ, G. BRANKOVIĆ, V. VUKOTIĆ, R. TARARAM, and J.A. VARELA
}

The possibility of mechanochemical synthesis of the lead magnesium niobate (PMN) powders of the composition $\mathrm{Pb}\left(\mathrm{Mg}_{1 / 3} \mathrm{Nb}_{2 / 3}\right) \mathrm{O}_{3}$ in iron vials was investigated. According to X-ray and energy-dispersive spectroscopy (EDS) analysis of the obtained powder mixtures, milling in iron vials resulted in incorporation of $\mathrm{Fe}$ and formation of $\mathrm{PFN}$ of composition $\mathrm{Pb}\left(\mathrm{Fe}_{1 / 2} \mathrm{Nb}_{1 / 2}\right) \mathrm{O}_{3}$ simultaneously with formation of PMN. Relative amounts of PMN and PFN were determined based on values of Curie temperature and lattice constant of perovskite phase. Although only $1 \mathrm{wt}$ pct of $\mathrm{Fe}$ was incorporated, a stoichiometry of the system was significantly changed, resulting in formation of pyrochlore phase and excess $\mathrm{MgO}$. Single-phase perovskite was obtained when the excess of $\mathrm{PbO}$ and $\mathrm{Nb}_{2} \mathrm{O}_{5}$ was added during mechanochemical synthesis. Because the dielectric properties were worse than expected, the alternative ways for improvement of dielectric properties were tried and discussed.

DOI: $10.1007 / \mathrm{s} 11661-007-9463-4$

(C) The Minerals, Metals \& Materials Society and ASM International 2008

\section{INTRODUCTION}

LEAD magnesium niobate (PMN) belongs to a family of complex perovskites with broad and large dielectric permittivity maxima at $-8{ }^{\circ} \mathrm{C}$ and $1 \mathrm{kHz}$, whose position shifts toward higher temperatures with frequency within a range of $20^{\circ} \mathrm{C} .^{[1]}$ The PMN also has very large electrostrictive and field-induced piezoelectric coefficients, low hysteresis losses, ${ }^{[2,3]}$ and other properties, which make PMN and its modifications suitable for applications such as chip capacitors, piezoelectric transducers, and actuators. ${ }^{[2,4]}$ The lead iron niobate (PFN) also belongs to the group of perovskite materials. It is interesting because of the extremely high dielectric constant, but also significantly higher Curie temperature of $\approx 112{ }^{\circ} \mathrm{C}^{[2]}$ The PMN-PFN is also considered as an attractive material with interesting possible applications. ${ }^{[2,3]}$ The synthesis of lead-based perovskite ceramics is always followed with the problem of stable cubic pyrochlore phase formation. Therefore, methods to obtain pyrochlore-free ceramics were widely studied and several methods were proposed: the columbite/ wolframite method ${ }^{[5,6]}$ simplified wolframite, ${ }^{[7]}$ reaction sintering ${ }^{[8]}$ and mechanochemical synthesis. ${ }^{[1,9]}$ In conventional solid-state and Columbite methods, the loss of $\mathrm{PbO}$ is inevitable when the multiple steps of phaseforming calcinations and subsequent sintering are carried out at high temperatures. Mechanochemical synthesis in high-energy mills could be a possible

Z. BRANKOVIĆ and G. BRANKOVIĆ, Senior Researchers, and V. VUKOTIĆ, Postdoctoral Student, are with the Institute for Multidisciplinary Research, Belgrade University, Kneza Višeslava 1a, 11000 Belgrade, Serbia. Contact e-mail: zorab@ibiss.bg.ac.yu R. TARARAM, Postdoctoral Student, and J.A. VARELA, Professor, are with the Instituto de Quimica, UNESP, 14800 Araraquara, SP, Brazil.

Manuscript submitted May 3, 2007.

Article published onlined February 14, 2008 solution to these problems. In this method, chemical reaction occurs during intensive milling of the precursor powders and steps of phase-forming calcinations can be avoided. It has to be emphasized that mechanochemical synthesis is usually connected with the problem of contamination from the milling media. Usually, a small amount of material from a milling media incorporates into the processed powder. The amount of incorporated material depends on the milling conditions (time and intensity), as well as on the mechanical properties of the milling media and processed material. Although this amount is usually small (about $1 \mathrm{wt}$ pct), it can have a dramatic influence on some properties, especially on the electrical parameters. Because of this fact, it is extremely important to determine the amount of incorporated material and the method of incorporation (incorporation into crystal lattice, formation of new phase through solid-state reaction with material being processed, or formation of simple mixture of powders). During the mechanochemical synthesis of PMN in iron media, the small amount of PFN can be formed, due to Fe incorporation into perovskite phase. Its influence on PMN properties has to be taken in account. Because the PFN also has excellent dielectric properties, it was expected that good properties will be retained even in the case of PFN formation.

In this work, the formation of PMN ceramics during mechanochemical synthesis in iron media was investigated.

\section{EXPERIMENTAL}

According to the chemical formula of the desired PMN ceramics, appropriate amounts of starting oxides ( $\mathrm{PbO}, \mathrm{MgO}$, and $\mathrm{Nb}_{2} \mathrm{O}_{5}$ ) were weighed, mixed, and further milled in a planetary ball mill (FRITSCH $\mathrm{GmbH}$, Idar-Oberstein, Germany). Milling conditions 
were the following: stainless steel jars $\left(V=500 \mathrm{~cm}^{3}\right)$ and balls $(d=13.4 \mathrm{~mm})$, ball-to-powder weight ratio of 40:1, air atmosphere, basic disc rotation speed of $317 \mathrm{~min}^{-1}$, rotation speed of discs with jars of $396 \mathrm{~min}^{-1}$, and milling time of 2 to 8 hours. Obtained powder samples were characterized by the methods of X-ray powder diffraction analysis (Siemens D-5000 1710 powder diffractometer with graphite-monochromatized $\mathrm{Cu} \quad K_{\alpha}$ radiation), scanning electron microscopy (SEM) (Topcon SM-300), and differential thermal analysis and thermogravimetric analysis (TGA) (Netszch-Thermische Analyse). Specific surface areas were determined using a Beunauer, Emmett, and Teller (BET) surface area analyzer (ASAP 2010, Micromeritics Instrument Corporation, Norcross, GA).

The powders were calcined at $450{ }^{\circ} \mathrm{C}, 600{ }^{\circ} \mathrm{C}$, and $800{ }^{\circ} \mathrm{C}$ during 1 hour. Further, the powders were isostatically pressed in pellets sized $8 \mathrm{~mm}$ in diameter and $1 \mathrm{~mm}$ in height and sintered in the temperature interval $1150{ }^{\circ} \mathrm{C}$ to $1250{ }^{\circ} \mathrm{C}$ for 1 and 2 hours in the $\mathrm{PbO}$ reach atmosphere. Some of the samples were additionally annealed at $900{ }^{\circ} \mathrm{C}$ for 1 hour. Ceramics samples were characterized by density measurements, SEM and X-ray diffraction (XRD) analysis. Electrical properties were investigated using a LCZ Meter Keithley 3330 (Keithley Instruments, Inc., Cleveland, $\mathrm{OH}$ ) at 1, 10, and $100 \mathrm{kHz}$ in the temperature interval $-15^{\circ} \mathrm{C}$ to $50^{\circ} \mathrm{C}$.

\section{RESULTS AND DISCUSSION}

The XRD analysis of the samples milled from 2 to 8 hours showed that the perovskite phase was already obtained after 2 hours of milling, but powders milled for 4 hours showed higher crystallinity and higher values of specific surface area, and were less agglomerated (Figures 1 and 2, Table I). Further prolongation of milling, i.e., further addition of mechanical energy to the system, resulted in refinement and amorphization of previously formed perovskite phase. Similar behavior was already observed in some other systems. ${ }^{[10-12]}$ Also,

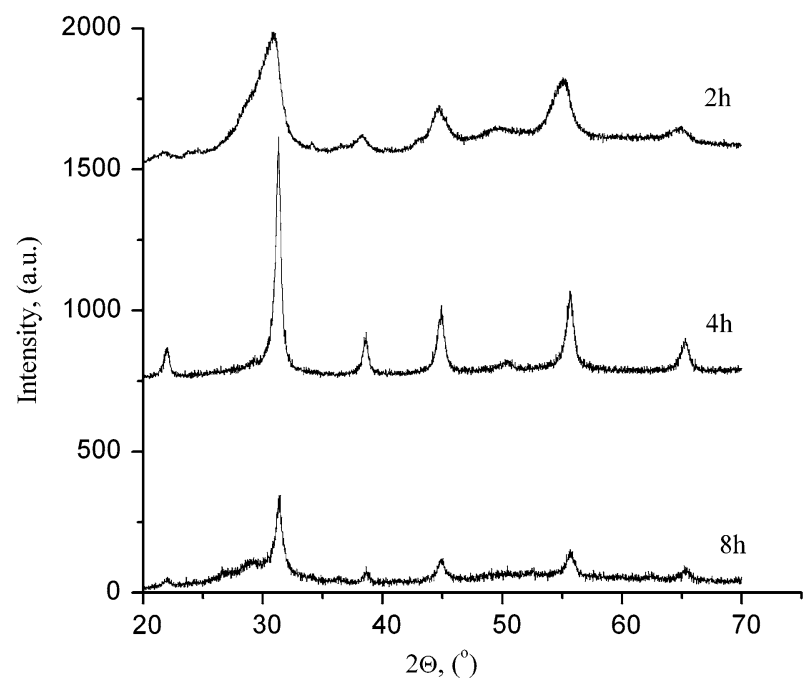

Fig. $1-\mathrm{XRD}$ of the powders milled for 2 to $8 \mathrm{~h}$.
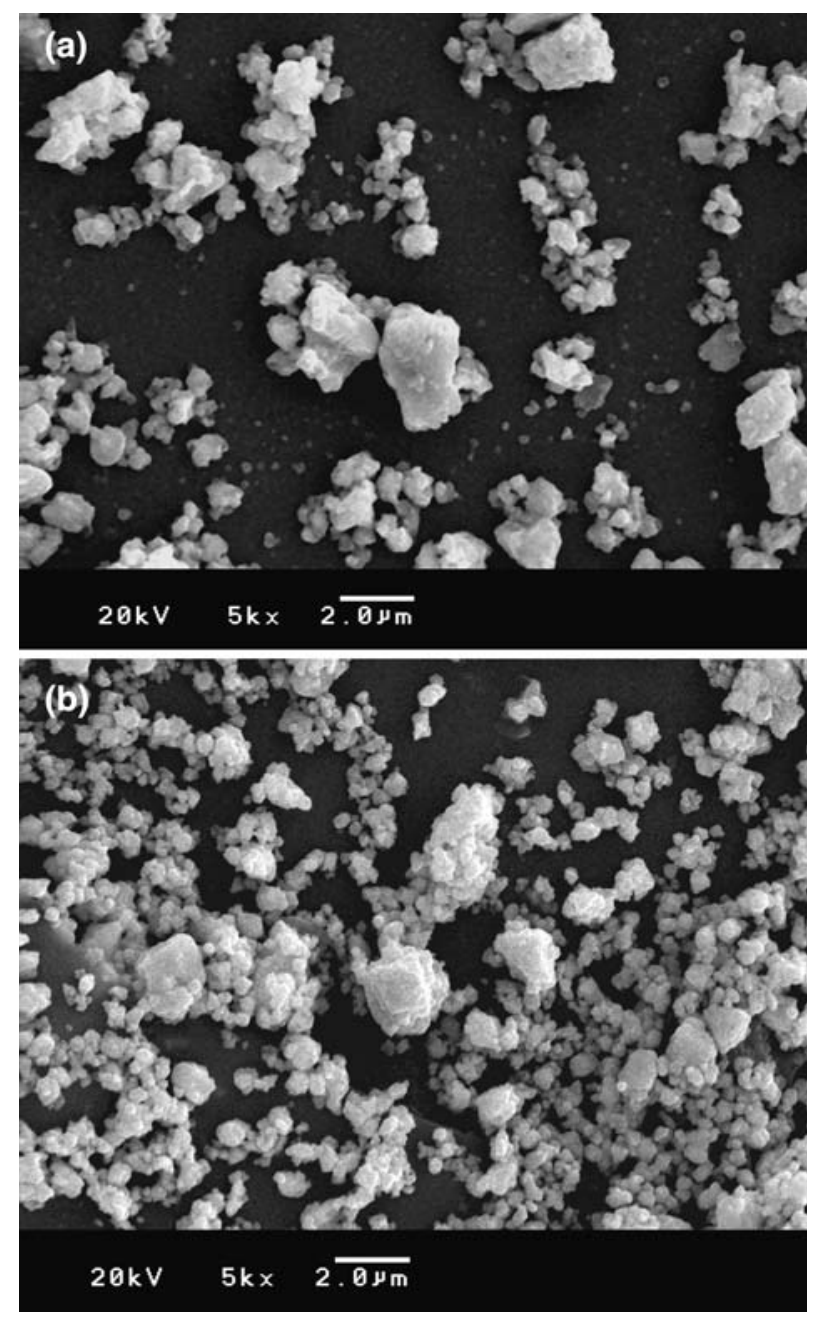

Fig. 2-SEM micrographs of the PMN powders milled for (a) $2 \mathrm{~h}$ and $(b) 4 \mathrm{~h}$.

Table I. Specific Surface Area of the Powders Milled for Different Times

\begin{tabular}{lcccc}
\hline Milling time $(\mathrm{h})$ & 2 & 4 & 8 \\
\hline $\begin{array}{c}\text { Specific surface } \\
\text { area }\left(\mathrm{m}^{2} / \mathrm{g}\right)\end{array}$ & $1.756 \pm 0.007$ & $4.60 \pm 0.02$ & $2.082 \pm 0.009$ \\
\hline
\end{tabular}

on the XRD pattern of the sample milled for 4 and 8 hours, it is possible to see a small peak at $2 \theta \approx 29 \mathrm{deg}$, which indicates the presence of a small amount of pyrochlore phase. This peak is more pronounced in the sample milled for 8 hours. Lower crystallinity of the perovskite phase and a more pronounced presence of the pyrochlore phase makes the powder milled for 8 hours less suitable for further processing. According to the results of XRD and the density measurements of the sintered samples, the calcination temperature of $450{ }^{\circ} \mathrm{C}$, sintering temperature of $1150{ }^{\circ} \mathrm{C}$, and sintering time of 2 hours were recommended as optimal conditions. Samples treated under these conditions reached 96.3 pct of theoretical density of PMN and showed the single-phase XRD pattern (Figure 3(a)). However, on SEM micrographs, it is possible to recognize grains of 

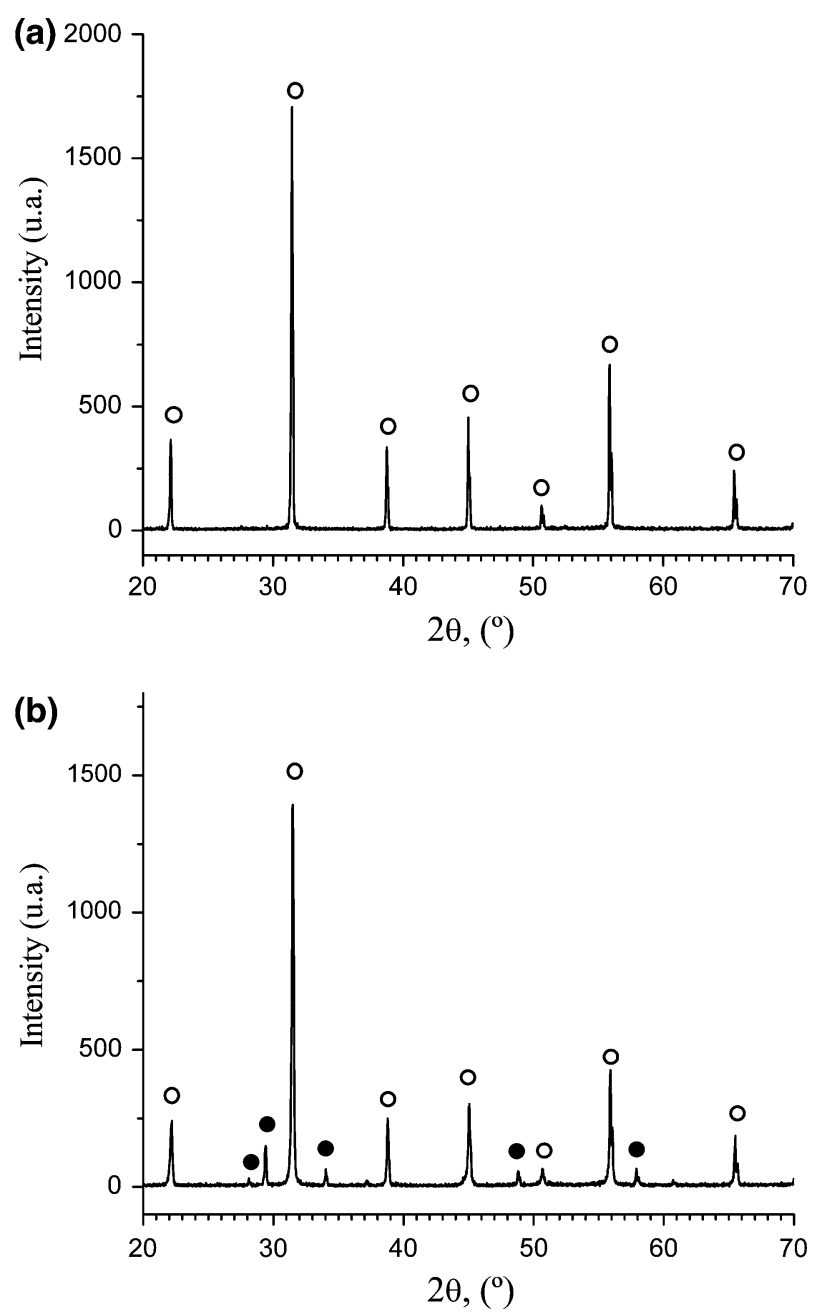

Fig. 3-XRD of the $(a)$ surface and $(b)$ interior of the sample milled for $4 \mathrm{~h}$ and sintered at $1150^{\circ} \mathrm{C}$ for $2 \mathrm{~h}$ : (O) perovskite and $(\bullet)$ pyrochlore.

different shapes and diameters (Figure 4), such as large trapezoidal grains of pyrochlore or smaller inclusions of darker $\mathrm{MgO}$-rich phase in the grains or at the grain boundaries, as was confirmed by EDS analysis. Also, samples were very dense with a low percentage of pores mainly located at grain boundaries. According to the micrograph from Figure 4, almost completely dense ceramics were obtained. Bearing in mind that the measured density (Archimedes method) was $96.5 \mathrm{pct}$ of the theoretical density of PMN, it can be concluded that the sample contained some other phases with lower density, for example, unreacted $\mathrm{MgO}$ or pyrochlore, and not only pure PMN. Because of this finding, the XRD analysis was repeated on the polished samples, and it was found that only a thin surface layer (Figure 3(a)) was single-phase perovskite; however, inside the samples, a pyrochlore-type phase was formed (Figure 3(b)). From the peak intensities, it was calculated that samples contained 9 pct of pyrochlore phase. This is a possible explanation for the differences in relative densities obtained from the Archimedes measurements (calculation based on assumption of pure PMN) and the results obtained from SEM micrographs.

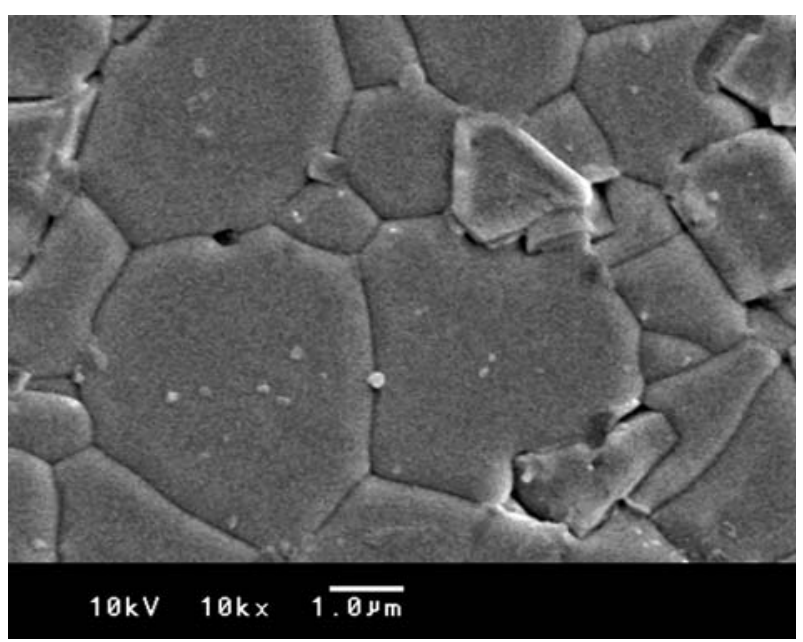

Fig. 4 -SEM micrograph of the samples milled for $4 \mathrm{~h}$ and sintered at $1150{ }^{\circ} \mathrm{C}$ for $2 \mathrm{~h}$.

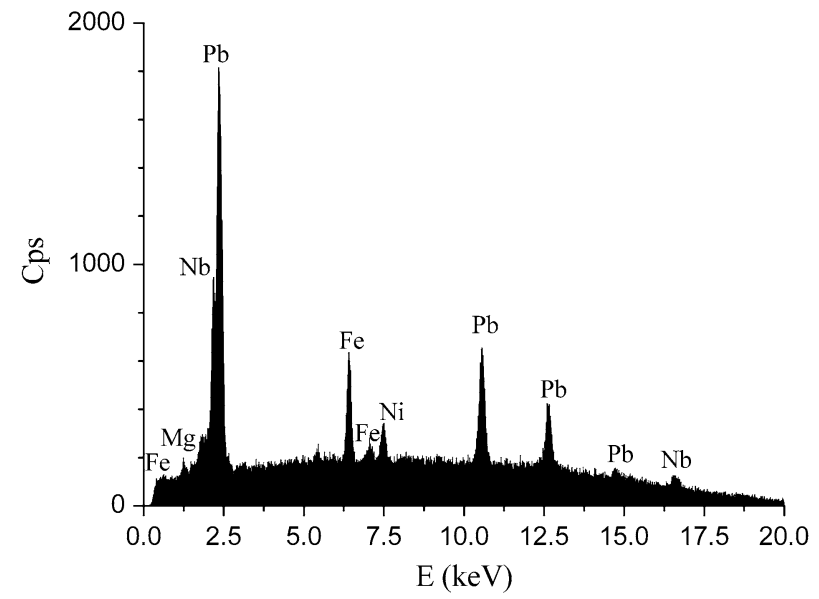

Fig. 5-EDS spectra of the samples milled for $4 \mathrm{~h}$.

Usually, researchers have a problem with losses of $\mathrm{PbO}$ during thermal treatment because of volatization of $\mathrm{PbO}$. This problem was prevented by thermal treatment in $\mathrm{PbO}$ reach atmosphere. The reason for disturbance of stoichiometry inside the samples, which resulted in pyrochlore phase formation, was found in incorporation of $\mathrm{Fe}$ into the powders during milling in iron media. The EDS analysis of milled powders confirmed the presence of Fe (Figure 5). The Fe from milling vials and balls entered the powders during milling and formed lead iron niobate. According to Jun and co-workers, ${ }^{[2]}$ there is a linear relationship between the lattice constant of perovskite phase in $(1-x) \mathrm{PMN}-x \mathrm{PFN}$ systems and the molar concentration of PFN, which satisfies Vegard's law and confirms the complete solubility in the PMN-PFN system. Comparison of our value of the lattice constant $(4.037 \AA)$ with their linear function ${ }^{[2]}$ indicated that approximately 25 pct of perovskite phase was PFN. Although it seems to be a large quantity, only 1 wt pct of Fe entering the system is needed to obtain this amount of PFN. The presence of PFN in the system should not have a dramatic influence on the dielectric constant, because it 
is a material with even higher values of dielectric constant than PMN, but it indirectly decays dielectric properties through disturbing stoichiometry of the starting powders. Comparison of $\mathrm{PMN}\left(\mathrm{Pb}\left(\mathrm{Mg}_{1 / 3} \mathrm{Nb}_{2 / 3}\right) \mathrm{O}_{3}\right)$ with $\mathrm{PFN}\left(\mathrm{Pb}\left(\mathrm{Fe}_{1 / 2} \mathrm{Nb}_{1 / 2}\right) \mathrm{O}_{3}\right.$ showed that the molar ratio in $\mathrm{PMN}$ is $1 \mathrm{~Pb}: 1 / 3 \mathrm{Mg}: 2 / 3 \mathrm{Nb}$ and in $\mathrm{PFN}$ the molar ratio is $1 \mathrm{~Pb}: 1 / 2 \mathrm{Fe}: 1 / 2 \mathrm{Nb}$. Replacing $\mathrm{Mg}$ with Fe resulted in spending $\mathrm{PbO}$ for reaction with $\mathrm{Fe}$ and the appearance of excess $\mathrm{Mg}$ and $\mathrm{Nb}$. The next consequence was formation of lead deficient phases, such as $\mathrm{Pb}_{1.83} \mathrm{Nb}_{1.71}$ $\mathrm{Mg}_{0.29} \mathrm{O}_{6.39}, \mathrm{~Pb}_{3} \mathrm{Nb}_{4} \mathrm{O}_{13}$ or $\mathrm{Mg}_{4} \mathrm{Nb}_{2} \mathrm{O}_{9}$. According to the X-ray results, mainly $\mathrm{Pb}_{1.83} \mathrm{Nb}_{1.71} \mathrm{Mg}_{0.29} \mathrm{O}_{6.39}$ or $\mathrm{Pb}_{3} \mathrm{Nb}_{4} \mathrm{O}_{13}$ pyrochlore phases were formed (both with the strongest maxima at $2 \theta \approx 29 \mathrm{deg}$ ). If the $\mathrm{Mg}_{4} \mathrm{Nb}_{2} \mathrm{O}_{9}$ was formed, it was of low crystallinity or under the detection limit. Further calculations and comparisons of compositions of perovskite and pyrochlore phases showed that a certain amount of nonreacted $\mathrm{MgO}$ persisted. This amount is too small or insufficiently crystalline to be detected by XRD.

Measurements of dielectric properties showed a dramatic decrease in dielectric constants and an increase of Curie temperature (Figures 6(a) and (b)) in comparison to the literature data for pure PMN. Because of the increase of PFN content, the Curie temperature increases with milling time, from $4.7{ }^{\circ} \mathrm{C}$ in samples milled 2 hours and $17.2^{\circ} \mathrm{C}$ in samples milled for 4 hours, up to $26.2^{\circ} \mathrm{C}$ in samples milled for 8 hours.
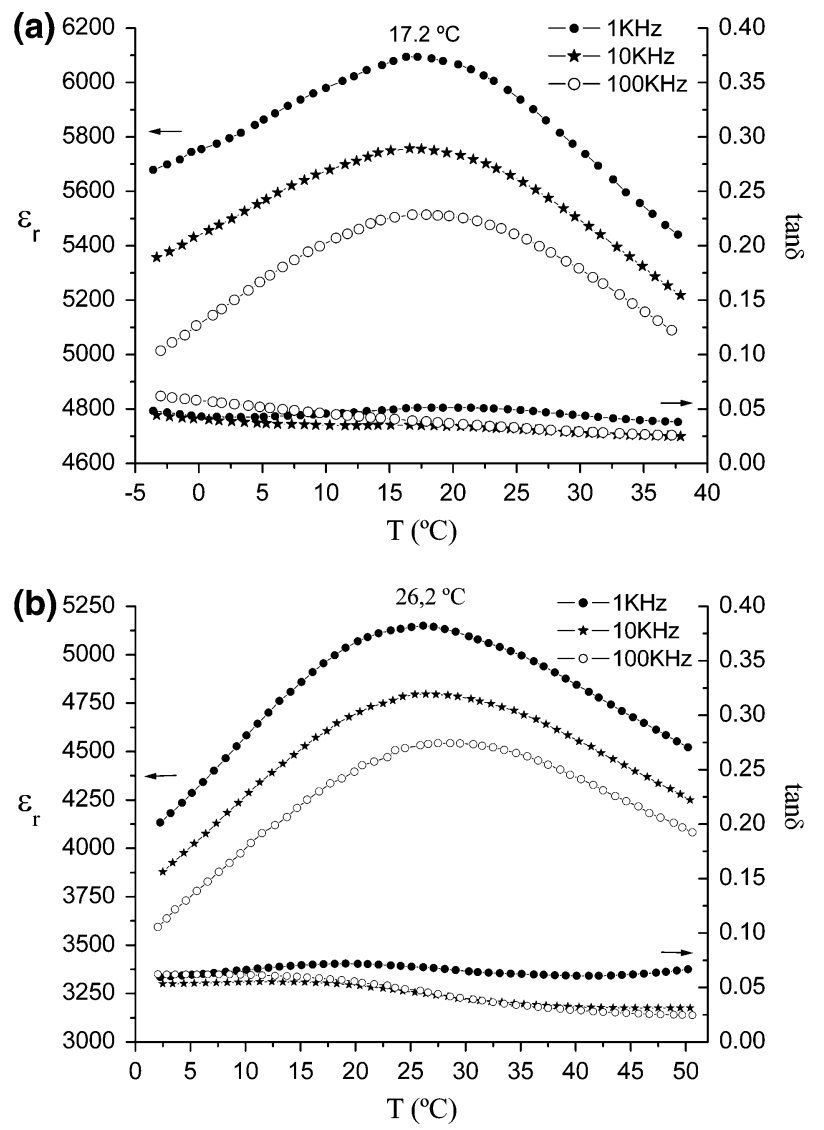

Fig. 6-Dielectric constant $\left(\varepsilon_{r}\right)$ and losses $(\tan \delta)$ as a function of temperature and frequency of the samples milled for $(a) 4 \mathrm{~h}$ and $(b)$ $8 \mathrm{~h}$, both sintered at $1150^{\circ} \mathrm{C}$ for $2 \mathrm{~h}$.
As shown by Jun et al., there is a linear relationship between the Curie temperature and composition of $(1-x)$ PMN- $x$ PFN ceramics. ${ }^{[2]}$ According to the Curie temperature value from our experiments, it is possible to calculate the approximate amount of PFN of 23 pct in samples milled for 4 hours, which is relatively close to the value calculated from XRD results, bearing in mind that the approximate values of Curie temperatures of PMN and PFN were used in the calculations. The maximum dielectric constant at $1 \mathrm{kHz}$ was only 6090 , which is significantly lower than the usually reported values. $^{[2,8]}$ The values of dielectric losses were low and satisfactory (Figure 6). It should be emphasized that the Curie temperature is almost independent of frequency, unlike the relaxors based on PMN. Such a behavior is typical of PFN ceramics and was already found and explained by some other authors in PMN-PFN systems, ${ }^{[2,13]}$ and also in some thin films. ${ }^{[14]}$

Some authors investigated the influence of pyrochlore on PMN dielectric properties and found that lead magnesium niobate-pyrochlore diphase mixtures retain relaxor properties and a high dielectric constant up to 18 vol pet of pyrochlore and that the dielectric properties are more influenced by microstructure and evolution of the grain boundary phase than by the pyrochlore phase. ${ }^{[15,16]}$ On the other hand, some investigations of the influence of the excess of $\mathrm{MgO}$ showed that it could result in a decrease of dielectric properties, ${ }^{[17]}$ although some other researchers obtained better properties with excess $\mathrm{MgO} .^{[18]}$ Anyway, the excess $\mathrm{MgO}$ in our samples was low in comparison to the amounts used in References 17 and 18 and probably cannot be treated as the cause of the decrease in dielectric constants. Obviously, the electrical properties of our samples were influenced by several factors. Improvement of dielectric properties could be achieved by providing stoichiometry and by the elimination of the pyrochlore phase. This could be done by the addition of excess $\mathrm{PbO}$ and $\mathrm{Nb}_{2} \mathrm{O}_{5}$ during milling, as was confirmed in our additional experiments when the pure perovskite phase was obtained inside the sintered samples, as well as in samples that were not grinded. $\mathrm{PbO}, \mathrm{Nb}_{2} \mathrm{O}_{5}$, and $\mathrm{MgO}$ were added in the

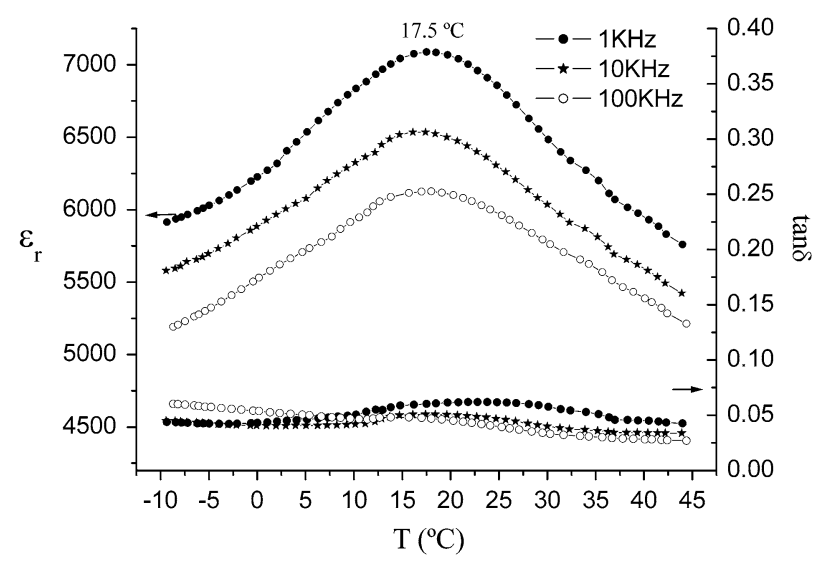

Fig. 7-Dielectric constant $\left(\varepsilon_{r}\right)$ and losses $(\tan \delta)$ as a function of temperature and frequency of the sample with excess of $\mathrm{PbO}$ and $\mathrm{Nb}_{2} \mathrm{O}_{5}$, milled for $4 \mathrm{~h}$ and sintered at $1150{ }^{\circ} \mathrm{C}$ for $2 \mathrm{~h}$. 
relative amounts necessary to retain the stoichiometry of the system, taking into account that about 25 pct of PFN was formed during milling. First analysis of PMN ceramics prepared in this way showed homogeneous microstructure and high density (up to $97.5 \mathrm{pct}$ of theoretical density), although the dielectric constants were still low, reaching 7100 at $1 \mathrm{kHz}$ and Curie temperature (Figure 7). The other possible explanation of relatively low values of dielectric constant could be found in the grain size, because it is well known that the value of the maximum dielectric constant increases with the grain size and vice versa. ${ }^{[3]}$ Comparison of the mean grain size of our best samples $(2.7 \mu \mathrm{m})$ with the literature data showed that other authors usually obtained similar or larger grains. ${ }^{[4,8]}$ Finally, the effect of the high defect concentrations in ball-milled samples should be considered, as was explained in the article published by Papet et al. ${ }^{[19]}$ A highly reactive powder with a high specific surface area has a large concentration of defects, which could immobilize the polar domains and consequently decrease the dielectric constant. To reduce the defect concentration and to relax the samples, additional annealing was performed. The samples were slowly heated to $900{ }^{\circ} \mathrm{C}$ and then annealed for 1 hour. According to the first results, the maximum dielectric constant was increased and reached 8500 . This result confirms at least the partial influence of the defect concentration on dielectric properties.

\section{CONCLUSIONS}

The possibility of mechanochemical synthesis of the PMN powders of composition $\mathrm{Pb}\left(\mathrm{Mg}_{1 / 3} \mathrm{Nb}_{2 / 3}\right) \mathrm{O}_{3}$ in iron vials was investigated. It was found that during mechanochemical synthesis in the iron media, the simultaneous formation of PMN and PFN occurred, resulting in loosing stoichiometry, pyrochlore phase formation, and the presence of a small excess of $\mathrm{MgO}$. The exact amounts of formed PFN and other phases were calculated based on the results of XRD, electrical measurements, density measurements, and SEM. The solution of the stoichiometry problem was found in preparing powder mixtures with excess $\mathrm{PbO}$ and $\mathrm{Nb}_{2} \mathrm{O}_{5}$ in accordance with the calculated final composition. The resulting ceramics were dense and pyrochlore free, with a Curie temperature of 17.2 and with a dielectric constant exceeding 7000. Significant improvement of the dielectric properties could be achieved only by promoting grain growth and by the reduction of defect concentration in highly active ball-milled powders. The reduction of defect concentration, which was achieved by additional annealing at $900{ }^{\circ} \mathrm{C}$, resulted in an increase of dielectic constant to the value of 8500 .

\section{ACKNOWLEDGMENTS}

This work was financially supported by the Ministry of Science of the Republic of Serbia (Project No. ON142040) and by Fundação de Amparo à Pesquisa do Estado de São Paulo, Brasil (FAPESP).

\section{REFERENCES}

1. M. Algueró, A. Moure, L. Pardo, J. Holc, and M. Kosec: Acta Mater., 2006, vol. 54, pp. 501-11.

2. S.-G. Jun, N.-K. Kim, J.-J. Kim, and S.-H. Cho: Mater. Lett., 1998, vol. 34, pp. 336-40.

3. L.E. Cross: Ferroelectrics, 1987, vol. 76, pp. 241-67.

4. S.M. Gupta and A.R. Kulkarni: J. Mater. Res., 1995, vol. 10, pp. 953-61.

5. S.L. Swartz and T.R. Shrout: Mater. Res. Bull., 1982, vol. 17, pp. $1245-50$.

6. T.R. Shrout, S.L. Swartz, and M.J. Haun: Am. Ceram. Soc. Bull., 1984, vol. 63, pp. 808-10.

7. Y.-C. Liou: Ceram. Int., 2004, vol. 30, pp. 567-79

8. Y.-C. Liou: J. Electroceram., 2004, vol. 12, pp. 187-90.

9. J. Wang, X. Junmin, W. Dongmei, and W.B. Ng: J. Am. Ceram. Soc., 1999, vol. 82, pp. 1358-60.

10. B.D. Stojanovic, C.O. Paiva-Santos, C. Jovalekic, A.Z. Simoes, F.M. Filho, Z. Lazarevic, and J.A. Varela: Mater. Chem. Phys., 2006, vol. 96, pp. 471-76.

11. D. Poleti, L.J. Karanović, M. Zdujić, Č. Jovalekić, and Z. Branković: Solid State Sci., 2004, vol. 6, pp. 239-45.

12. Z. Branković, G. Branković, Č. Jovalekić, Y. Maniette, M. Cilense, and J.A. Varela: Mater. Sci. Eng. A, 2003, vol. 345, pp. 243-48.

13. Y. Yu, C. Feng, C. Li, Y. Yang, and H. Yan: Jpn. J. Appl. Phys., 2001, vol. 40, pp. 2348-56.

14. F.M. Pontes, S.H. Leal, E.R. Leite, E. Longo, P.S. Pizani, A.J. Chiquito, M.A.C. Machado, and J.A. Varela: Appl. Phys. A, 2005, vol. 80 , pp. $813-17$.

15. A.L. Costa, C. Galassi, G. Fabbri, E. Roncari, and C. Capiani: J. Eur. Ceram. Soc., 2001, vol. 21, pp. 1165-70.

16. J. Chen and M.P. Harmer: J. Am. Ceram. Soc., 1990, vol. 73, pp. 68-73.

17. D. Saha, A. Sen, and H.S. Maiti: Mater. Res. Bull., 2000, vol. 35, pp. 305-14.

18. H.-C. Wang and W.A. Schulze: J. Am. Ceram. Soc., 1990, vol. 73, pp. 825-32.

19. P. Papet, J.P. Dougherty, and T.R. Shrout: J. Mater. Res., 1990, vol. 5 , pp. 2902-09. 